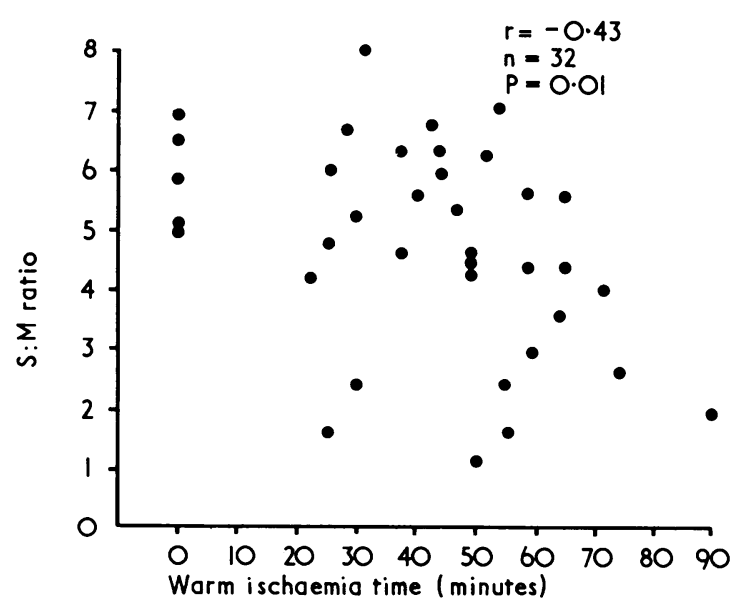

FIG 6-S:M ratio of all human kidney biopsy specimens showing correlation with warm ischaemia time.

ischaemia time. All kidneys with an $S: M$ ratio over 3 have functioned. Four cadaver kidneys with an $S: M$ ratio under 2 did not function, and on the basis of animal studies this was predicted before transplantation. As the whole technique is in an experimental stage we could not deny the use of these kidneys for transplantation. The critical range of $S: M$ ratio where function is less easy to determine is between 2 and 3. Four kidneys in this range worked, one 24 hours after transplan- tation and the other three after prolonged periods of tubular necrosis. Biopsy of two of these 14 days after transplantation showed extensive tubular atrophy and patchy cortical necrosis. Further use of the test is required to evaluate the critical area between 2 and 3 .

${ }^{125}$ I-iodohippurate uptake by donor kidney slices can be applied to kidneys stored on ice or by pulsatile perfusion, or while still in situ. Preservation by pulsatile perfusion of human kidneys did not seem to cause either improvement or deterioration in the $S: M$ ratio. This contrasted with the observation that prolonged cold storage of rat kidneys caused a deterioration in the $S: M$ ratio.

We acknowledge the help and advice given by Professor R Shackman. Requests for reprints should be addressed to Mr G Williams Department of Surgery, Royal Postgraduate Medical School, Hammersmith Hospital, Du Cane Road, London W12 0HS.

\section{References}

${ }^{1}$ National Organ Matching Report. Bristol, October, 1973.

2 Carroll, R N P, Chisholm, G D, and Shackman, R, Lancet, 1969, 2, 551.

${ }^{3}$ Hamshere, R J, and Lipscombe, J, unpublished data.

4 Slapak, M, and Rodgers, S, Transplantation Proceedings, 1975, 3, Suppl No 1, p 569.

${ }^{5}$ Baxby, K, et al, Lancet, 1974, 2, 977.

${ }^{6}$ Calman, K C, and Bell, P R F, British fournal of Surgery, 1973, 60, 322.

' Sells, R A, McLoughlin, R A, and Tyrrell, I, British fournal of Surgery, $1974,61,326$

${ }^{8}$ Rogers, S, and Slapak, M, British fournal of Surgery, 1974, 61, 98.

9 Hall, C L, et al, British Medical fournal, 1975, 3, 667.

\title{
Superficial carcinoma of the stomach
}

\author{
G MACHADO, J D DAVIES, A J C TUDWAY, P R SALMON, A E READ
}

British Medical fournal, 1976, 2, 77-79

\section{Summary}

Nine cases of superficial gastric carcinoma have been detected with upper gastrointestinal endoscopy in Bristol in the past two years. This contrasted with only six cases found from postoperative gastrectomy specimens examined in the previous eight years. It is often difficult to distinguish a superficial carcinoma from a benign ulcer, and endoscopic diagnosis is effective only if multiple biopsy specimens are taken. Endoscopy should also be repeated and multiple specimens taken until the lesion has healed; even malignant ulcers may heal, and any healed area that is depressed with interrupted mucosal folds should be suspected of malignancy. The endoscopic and histological appearances, the age of the patients, and the clinical behaviour of the disease resembled descriptions of the disease, principally from Japan. Superficial gastric carcinoma is probably underdiagnosed in Britain.

\footnotetext{
University Departments of Medicine and Histopathology, Bristol Royal Infirmary, Bristol BS2 8HW

G MACHADO, MD, consultant assistant professor, Universidade Federal do Rio de Janeiro

J D DAVIES, MD, MRCPATH, consultant senior lecturer in pathology

A J C TUDWAY, MB, BCHIR, lecturer in pathology

P R SALMON, MRCP, consultant senior lecturer in medicine

A E READ, MD, FRCP, professor of medicine
}

\section{Introduction}

Japanese experience has shown a remarkable five-year survival rate of over $90^{\circ}{ }_{0}$ in surgically treated patients with carcinoma of the stomach limited to the mucosa or submucosa (superficial carcinoma). ${ }^{2}$ This is in striking contrast to an overall survival rate of about $15^{\circ}$ in the United Kingdom ${ }^{3}{ }^{4}$ and the United States. ${ }^{5}$ This low survival rate is probably due to the infrequent detection of superficial gastric carcinoma. ${ }^{6-8}$ Over a third of cases in Japan are now detected at this stage. ${ }^{12}$ The Japanese relate the increased diagnosis of superficial gastric carcinoma to the widespread use of endoscopic examination with biopsy. In view of its potential importance we report our experience of the changing incidence of superficial carcinoma of the stomach in a British centre.

\section{Methods}

Two groups of patients were studied. The material received in the university department of histopathology from all patients submitted to gastric resection between January 1965 and May 1975 was reviewed. The second group included all patients referred to the digestive endoscopy unit, university department of medicine, Bristol Royal Infirmary, from its establishment in December 1969 to May 1975.

Endoscopic examinations were performed as reported ${ }^{9}$ with the ACMI F-8 fibrescope, and biopsy specimens were taken when the appearances suggested malignancy or when ulceration or polyps were found. The paraffin-embedded biopsy tissue obtained at gastroscopy was treated as described, ${ }^{10}$ and the stomachs resected between 1973 and 1975 were examined according to a modification of the method of Mochizuki."11 The macroscopic classification of superficial gastric carcinoma laid down in 1962 by the Japanese Society for Gastroenterological Endoscopy ${ }^{12}$ was adopted (see figure). 


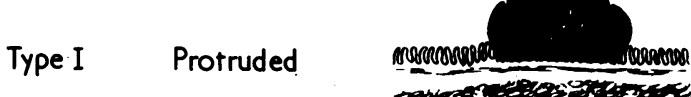
等

(a) Elevated

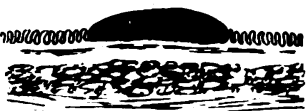

Type II Superficial

Flat

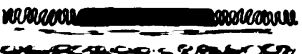

(c) Depressed
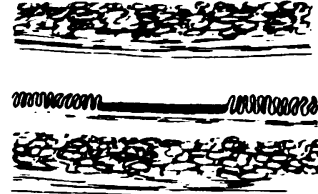

Type III Excovoted

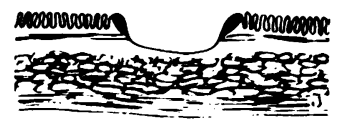

Macroscopic classification of superficial gastric carcinoma according to the Japanese Society for Gastroenterological Endoscopy, 1962.

\section{Results}

Between January 1965 and May 1975 there were 15 cases of superficial gastric carcinoma seen at the Bristol Royal Infirmary; these occurred in nine men and six women aged 45 to 79 years. The first six cases, seen before 1973, were diagnosed incidentally during pathological examination of stomachs resected for apparently benign ulcers. The subsequent nine cases were diagnosed preoperatively in patients seen in a routine endoscopy clinic during the past two years. The percentage of all cases of carcinoma of the stomach that were diagnosed in the superficial stage at endoscopy increased from 3.9\% in 1973 to $14.3^{\circ} \%$ in 1974 and $20^{\circ} \%$ in the first five months of 1975 (table I).

Carcinoma was detected in endoscopic biopsy specimens in six of the nine patients with superficial gastric carcinoma. In the other three patients only severe dysplasia was found, but gastrectomy was performed because of suspicious endoscopic appearances and lack of healing or repeated bleeding. The mucosal carcinoma in these cases was minute and detected only after detailed pathological examination of the resected stomach. Overall $41 \%$ of endoscopic biopsy fragments contained carcinoma (table II).

Macroscopically 13 of the 15 patients showed ulcerated superficial lesions (types IIc, III, or combined), and one had a polypoid (type I) and one a flat (type IIb) lesion. Histopathological examination of the resected stomachs showed seven cases of submucosal invasion, seven of mucosal stromal invasion, and only one of apparent in-situ or intratubular carcinoma. No case of borderline atypia ${ }^{13}$ or of superficial carcinoma with nodal metastasis was included in this series.

There were four deaths in the whole series, including one from postoperative bronchopneumonia. In no patient was there any evidence of local recurrence or metastasis of the tumour.

\section{Discussion}

A possible reason for the disappointing survival rate in patients with gastric carcinoma after surgery in the United Kingdom may be the small proportion of superficial carcinomas detected. This low rate of detection may be due to infrequent use of endoscopy, or superficial carcinoma may be a type of lesion that is common in Japan and rare in Europe. The latter explanation seems unlikely in view of the increasing rate of detection of superficial gastric carcinoma in the Continental centres that are using endoscopy. ${ }^{14-16}$ Similarly, the increased use of endoscopy in Bristol has resulted in considerably more cases of gastric carcinoma being diagnosed at the superficial stage. In the past two years the number of cases detected by gastroscopy was nearly twice that found in surgical specimens during the preceding eight years, ${ }^{17}$ representing about $10 \%$ of all the cases of gastric cancer diagnosed in the endoscopy unit (table I).

This improvement in endoscopic diagnosis was probably due to the increased number of biopsy fragments taken during the endoscopic examination; at least six fragments were always taken. ${ }^{17}$ This technique has been routinely used by one of us (GM) since 1968 in Brazil, ${ }^{18}$ in accordance with the accepted practice in Japan ${ }^{19}$ and Germany. ${ }^{16}$ Even in experienced hands, however, only about $40-50 \%$ of biopsy fragments contain carcinoma, ${ }^{15}$ a proportion similar to that found in our material (table II).

Most of our patients presented with ulcerated superficial carcinoma, which agrees with what is commonly reported..$^{15}$ The problem of distinguishing between benign and malignant ulcers is well known, and it is commonly found that $4-12 \%$ of apparently benign ulcers are malignant. ${ }^{20-22}$ Possibly this is because endoscopy is still not used routinely and radiology is thought to be sufficient for detecting and following up gastric ulcers. ${ }^{23}$ Even the endoscopic diagnosis is not easy, however, and several points must be kept in mind.

Firstly, superficial carcinoma type IIc is often similar to a benign erosion or shallow ulcer and it is practically impossible to distinguish a type III carcinoma from a chronic peptic ulcer, especially in the active stage. ${ }^{1024}$ Secondly, the concept that malignant ulcers rarely show significant healing ${ }^{25}$ has been challenged after several well-documented cases of healing of malignant ulcers were reported. ${ }^{28}{ }^{27}$ Sakita $^{27}$ pointed out that in most cases even the time of healing is similar to that commonly seen with benign ulcers. ${ }^{28}$ Thirdly, the time that an ulcer takes to heal is difficult to determine and it varies with each patient. ${ }^{29}$ Therefore to ensure that the correct diagnosis is made endoscopy should be performed about every 30 days until complete healing has occurred. Multiple biopsies must be taken in every case from the edges, the surrounding mucosa, and occasionally from the base of the ulcer. Fourthly, an ulcer that has healed but which presents as a depressed area with interrupted mucosal folds should be suspected of malignancy. Finally, the occurrence of severe dysplasia in biopsy fragments must be

TABLE I-Cases of carcinoma of the stomach diagnosed by endoscopy 1969-75

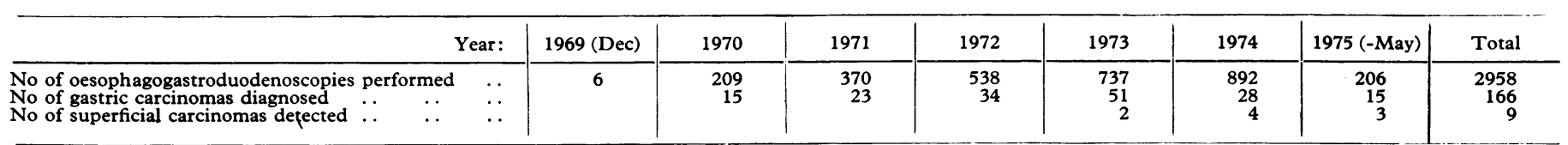

TABLE II-Incidence of positive findings on endoscopic gastric biopsy. Figures in parentheses indicate number of specimens showing severe dysplasia

\begin{tabular}{|c|c|c|c|c|c|c|c|c|c|c|c|c|c|c|}
\hline & Case No: & 1 & 2 & & & 4 & & $5^{*}$ & & 6 & 7 & 8 & 9 & Total \\
\hline $\begin{array}{l}\text { No of biopsy fragments taken } \\
\text { No of positive specimens }\end{array}$ & $\begin{array}{ll} & \\
& \end{array}$ & $\begin{array}{l}7 \\
6\end{array}$ & $\begin{array}{l}9 \\
7\end{array}$ & $\begin{array}{c}6 \\
0(2)\end{array}$ & $\begin{array}{r}10 \\
6\end{array}$ & $\stackrel{6}{0}$ & $\stackrel{6}{(1)}$ & $\begin{array}{c}8 \\
0(3)\end{array}$ & $\begin{array}{l}9 \\
5\end{array}$ & $\stackrel{7}{0}$ & $\begin{array}{l}9 \\
7\end{array}$ & $\begin{array}{l}6 \\
0(3)\end{array}$ & $\begin{array}{l}8 \\
6\end{array}$ & $37 \stackrel{91}{(41 \%)}$ \\
\hline
\end{tabular}

*Two patients (cases 3 and 5) were examined more than once. 
regarded as an indication for more careful management, and surgical treatment should be considered.

Further studies are necessary to compare this disease in the United Kingdom with that in Japan. The clinical and morphological findings and limited follow-up data in our patients support the view that the disease is the same in both countries, although we cannot yet estimate the prognosis in the cases diagnosed endoscopically. Nevertheless, all six patients who underwent operation for what were thought to be benign conditions were alive and well after five years. Endoscopy could reasonably be introduced for all high-risk groups of patients, including those with pernicious anaemia, chronic atrophic gastritis, and gastric polyps, those who have undergone gastrectomy, and those over 45 years of age with radiologically negative persistent dyspepsia.

Okabe $^{30}$ emphasises that many cases of carcinoma of the stomach may remain in a superficial stage for a long period. Thus superficial carcinoma can be diagnosed at a younger age than the advanced disease. This should also decrease the incidence of surgical complications and give a better prognosis.

Requests for reprints should be addressed to: Dr G Machado, Rua Almte. Gonçalves 35 apto 501, Copacabana Zc-37, Rio de Janeiro, Brasil.

\section{References}

1 Yamagata, S, et al, in Proceedings of the 3rd World Congress of Gastroenterology, vol 1, p 487. Tokyo, Nissha Printing Co, 1967.

2 Kidokoro, T, in Early Gastric Cancer, ed T Murakami, p 45. Tokyo, University of Tokyo Press, 1971.

${ }^{3}$ Naish, J M, and Read, A E A, Basic Gastro-enterology, p 62. Bristol, John Wright and Sons Ltd, 1974
${ }^{4}$ Brookes, V S, Waterhouse, J A H, and Powell, D J, British Medical fournal, 1965, 1, 1577.

5 Hoerr, S O, Surgery, Gynecology and Obstetrics, 1973, 137, 205.

${ }^{6}$ Prolla, J C, Kobayashi, S, and Kirsner, J B, Archives of Internal Medicine, 1969, 124, 238.

' Gear, M W L, et al, British Fournal of Surgery, 1969, 56, 739.

8 Ashby, B S, Gut, 1974, 15, 512.

9 Machado, G, fornal Brasileiro de Medicina, 1969, 17, 73 (in Portuguese).

10 Machado, G, et al, Aktuelle Gastrologie, 1975, 4, 65.

${ }^{11}$ Davies, J D, Tudway, A J C, and Machado, G, fournal of Clinical Pathology, in press.

12 Murakami, T, in Early Gastric Cancer, ed T Murakami, p 53. Tokyo, University of Tokyo Press, 1971.

13 Sano, R, in Early Gastric Cancer, ed T Murakami, p 81. Tokyo, University of Tokyo Press, 1971

${ }^{14}$ Liguory, C, et al, Mises a four d'Hepato-gastro-enterologie, 1974, 2, 31.

${ }^{15}$ Miller, G, and Kauffmann, M, Proceedings of the 3rd International Congress of Gastrointestinal Endoscopy, p 26. Mexico, Imprenta Madero, 1974.

16 Elster, K, et al, Endoscopy, 1975, 7, 5

17 Machado, G, Gastric Carcinoma. An Endoscopic and Biochemical Appraisal. MD thesis, University of Bristol, 1975.

${ }^{18}$ Machado, G, and Rubens, J, in Anais do XII Congresso Brasileiro e PanAmericano de Cirurgia, p 125. Rio de Janeiro, colégio Brasileiro de Cirurgiões, 1971 (in Portuguese).

19 Ishioka, K, Stomach and Intestine, 1971, 5, 829.

20 Grossman, M I, Gastroenterology, 1971, 61, 635.

${ }^{21}$ Mowat, N A G, Needham, C D, and Brunt, P W, Quarterly fournal of Medicine, 1975, 173, 45.

${ }^{22}$ Montgomery, R D, and Richardson, D P, Quarterly fournal of Medicine, $1975,176,591$.

${ }^{23}$ Salter, R H, Lancet, 1975, 2, 863

$24 \mathrm{Kawai}, \mathrm{K}$, et al, Endoscopy, 1970, 2, 82.

${ }^{25}$ Bachrach, W H, Surgery, Gynecology and Obstetrics, 1962, 114, 69.

${ }^{26}$ Imai, T, and Okubo, T, Stomach and Intestine, 1968, 3, 677.

27 Sakita, T, et al, Gastroenterology, 1971, 60, 835.

28 Doll, R, Scottish Medical fournal, 1964, 9, 183.

29 Ichikawa, H, Clinics in Gastroenterology, 1973, 2, 329.

${ }^{30}$ Okabe, H, in Early Gastric Cancer, ed T Murakami, p 67. Tokyo, University of Tokyo Press, 1971.

\title{
Whole-body in-vivo neutron activation analysis in assessing treatment of renal osteodystrophy with I-alpha-hydroxycholecalciferol
}

\author{
R B NAIK, P GOSLING, C P PRICE, B H B ROBINSON, J T DABEK, D A HEATH, \\ H M JAMES, J A KANIS, R SMITH
}

British Medical fournal, 1976, 2, 79-83

\section{Summary}

Four selected adults with different patterns of osteodystrophy receiving regular dialysis were treated with

\footnotetext{
Renal Unit and Department of Clinical Chemistry, East Birmingham Hospital, Birmingham B9 5ST

R B NAIK, MRCP, honorary senior registrar

P GOSLING, PHD, biochemist

C P PRICE, PHD, principal biochemist

B H B ROBINSON, FRCP, consultant physician

Departments of Experimental Pathology and Medicine, University of Birmingham, Birmingham

J T DABEK, MRCP, research fellow

D A HEATH, MRCP, senior lecturer

H M JAMES, PHD, research fellow

Metabolic Unit, Nuffield Departments of Orthopaedic Surgery and Medicine, University of Oxford, Oxford

J A KANIS, MRCP, research fellow

R SMITH, FRCP, consultant physician
}

1- $\alpha$-hydroxycholecalciferol $\left(1-\alpha-\mathrm{OHD}_{3}\right) \quad 0.5-2 \mu \mathrm{g} /$ day for 10 to 12 months. In two patients, one with osteitis fibrosa and the other with osteomalacia, significant biochemical, radiological, and histological improvements occurred, and total body calcium measured by in-vivo neutron activation analysis increased. In two patients, in whom there were no increases of whole-body calcium, neither biochemical improvement nor healing of bone lesions occurred during the study; in one of these patients the effect of 1- $\alpha-\mathrm{OHD}_{3}$ on bone resorption may have contributed to loss of body calcium and deterioration of bone disease. 1- $\alpha-\mathrm{OHD}_{3}$ may therefore be a valuable adjunct in the treatment of only some patients with renal osteodystrophy. Whole-body in-vivo neutron activation seems to provide a sensitive and non-invasive index of early response to treatment.

\section{Introduction}

Cholecalciferol (vitamin $\mathrm{D}_{3}$ ) is converted in the liver to 25hydroxycholecalciferol, the main circulating form of vitamin D. ${ }^{2}$ Further hydroxylation in the $1-\alpha-$ position to $1-\alpha, 25-$ dihydroxycholecalciferol $\left(1-\alpha, 25-(\mathrm{OH})_{2} \mathrm{D}_{3}\right)$ occurs in the 